\title{
A POSSIBLE EFFECT OF ATMOSPHERIC CIRCULATION IN THE DAILY VARIATION OF THE EARTH'S MAGNETIC FIELD
}

\author{
OLIVER REYNOLDS WULF \\ U.S. Weather Bureau; Gates and Crellin Laboratories of Chemistry, California Institute of Technology, Pasadena, Calif.
}

[Manuscript received June 21, 1963; revised July 29, 1963]

\section{ABSTRACT}

\begin{abstract}
The daily variation of the horizontal intensity of the earth's magnetic field at Honolulu exhibits seasonal features that are not related in a simple way to solar declination. These are illustrated here in monthly curves of the daily variation for quiet days averaged over a considerable number of years. It is believed that these features may arise from the seasonal variation of the large-scale air circulation in the lower ionosphere. It is suggested that a study of the daily magnetic records against large-scale features of daily meteorological maps of the upper stratosphere might find related changes occurring at the two levels and might make possible the use in this way of abundant geomagnetic data in meteorological research.
\end{abstract}

\section{INTRODUCTION}

Large-scale circulation of air (large-scale prevailing winds) in the lower ionosphere should affect in some measure the daily variation of the earth's magnetic field if the daily variation arises, in accord with the generally accepted dynamo theory, from daily-periodic ionospheric winds. Indeed, the daily-periodic winds might be thought of as a daily distortion of the prevailing winds there. In 1945 the author [12] pointed this out, since large-scale circulation of air in the lower ionosphere seemed likely, and attempted shortly after [13] a comparison of the daily variation of the field with patterns of atmospheric circulation near the base of the stratosphere as afforded by meteorological maps then available.

The daily variation of the earth's magnetic field at Honolulu may offer an illustration of such an effect of atmospheric circulation. Howe [2] has earlier called attention to an anomaly in this variation.

\section{PRESENTATION OF DATA ${ }^{1}$}

In figure 1 are shown, for 10 selected quiet days of each month, the 12 monthly-averages of the daily variation of the horizontal intensity at Honolulu for the 20 years 1917-36, uncorrected for non-cyclic change. The data for each year were taken from the tables of the diurnal variation in the biennial publications of the Honolulu Magnetic Observatory of the U.S. Coast and Geodetic Survey.

The figures have been prepared with respect to solar declination. The monthly diagram for December, when

\footnotetext{
1 Concerning the general subject of regular motions of air in the ionosphere and their geomagnetic relationships the reader is referred to an article by Cbapman [1]. The reader's attention is also called to a recent article by van Sabben [8] and to an artiele by Vestine [0].
}

the sun is farthest south of the observatory, is at the top, and that for June, when the sun is practically overhead at noon, at the bottom. The remaining 10 monthly diagrams are so arranged that months having roughly the same average solar declination are horizontally adjacent to one another, as for example, April and August. With calendar months, however, the difference in the monthly average declinations for such pairs of months may be several degrees, and, for example, the declination for May is larger than that for August by only a little more than the amount by which that for April is smaller. For the average of 10 quiet days in a month this difference in solar declination may be even greater since the 10 days are not in general distributed uniformly throughout the month. However, averaging for the month over a number of years should tend to minimize such added difference.

In figure 1 it can be seen that there are differences of range and of form in the daily variation that do not follow solar declination in a simple way. They seem to involve seasonal changes in some other less regular factor.

Large range in the 20-yr. averages of figure 1 occurs in March and April. In contrast, September and August, with roughly the same solar declination respectively, have small range. (August may also be compared with May since the mean declination for August, as mentioned above, lies only a little closer to that for April than to that for May.) There appears to be a major seasonal difference here caused by something more than a difference in solar declination.

Another feature shown by figure 1 is a difference of form, a tendency for a secondary minimum in the vicinity of the 8th hour in the daily variations of September and October that is absent in March and February. It is 


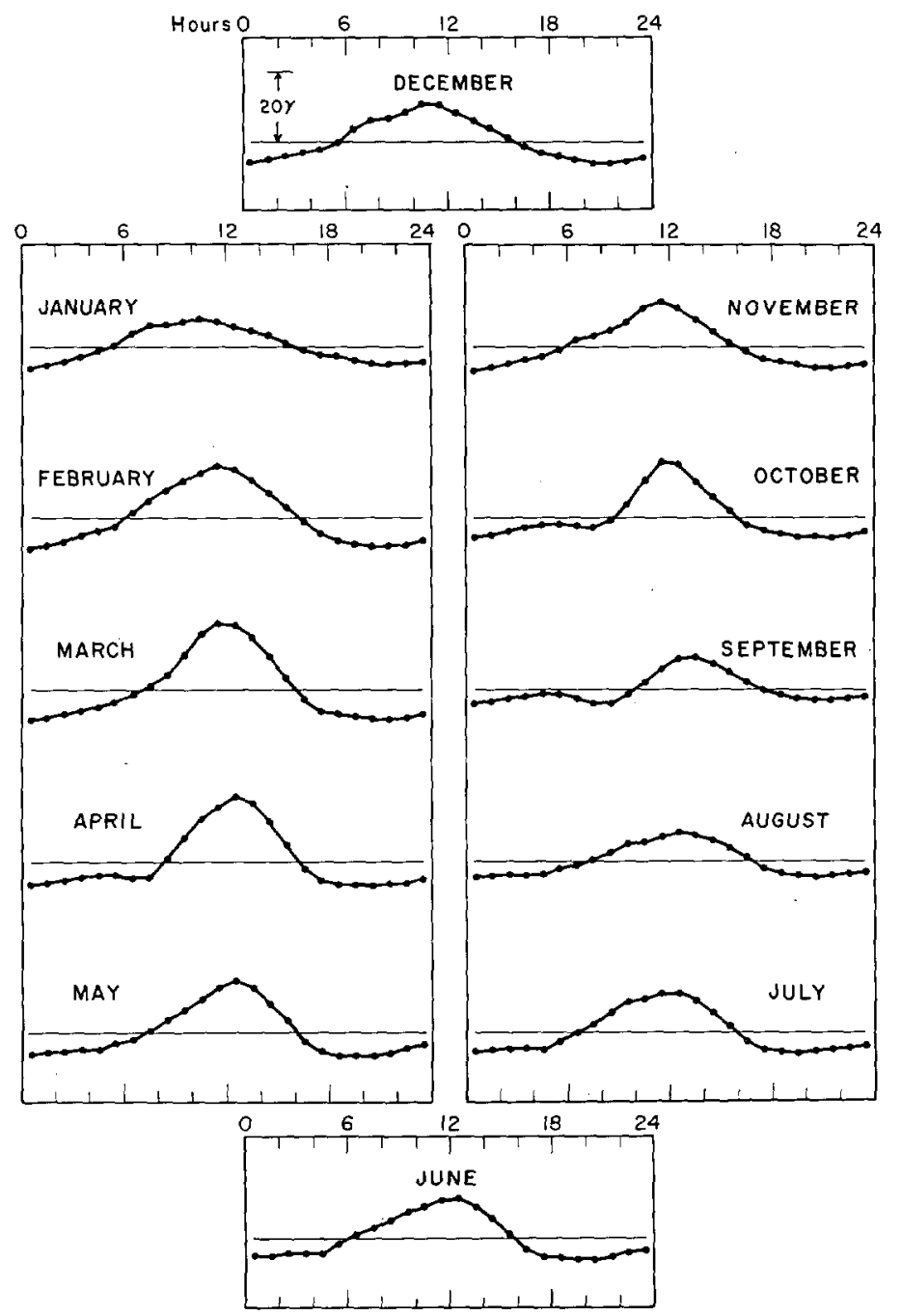

FIGURE 1.-Daily variation of horizontal intensity in gammas of the earth's magnetic field at Honolulu. Monthly averages for 10 selected quiet days of each month for the 20 years 1917-36. 165 th west meridian time.

present in April and the mean declination for September lies only a little closer to that of March than to that of April. However, the presence of this minimum in October and its intensity in September leave little doubt that, at two different times on opposite sides of the year with the sun at the same declination, this secondary minimum was present, in the average, on the fall side of the year but not on the spring side, though it was present on the spring side a little later in the season somewhat less intensely.

To inquire in how far these monthly averages are representative of the 20 years, the data were divided into two sets of 10 years each. The division chosen was the five years prior to and including both sunspot minima, here 1919-23 and 1929-33, and the remaining 10 years, of greater average sunspottedness, 1917-18, 1924-28, and 1934-36. The results, arranged in the same form as those in figure 1, are shown in figures 2 and 3.

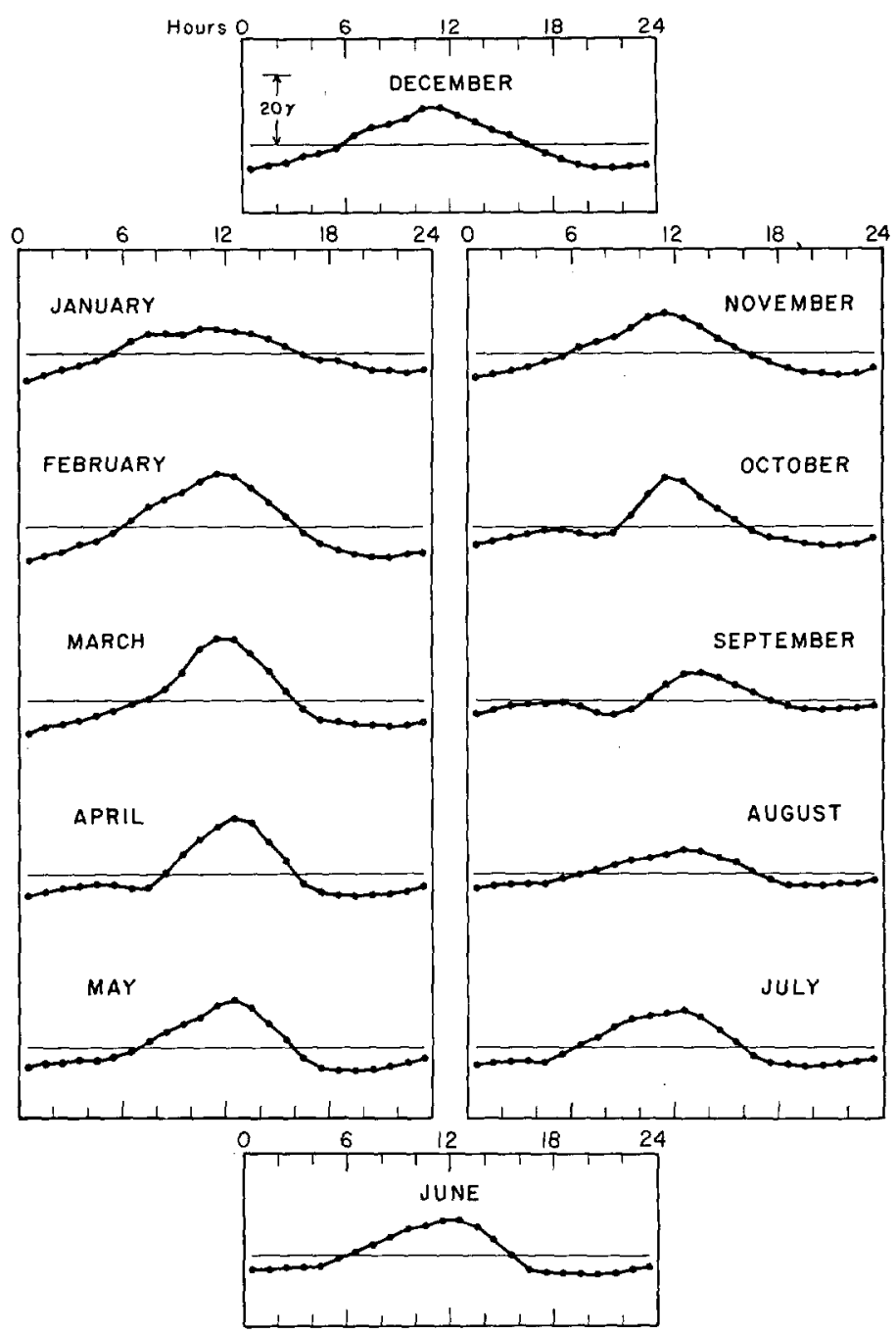

FIGURe 2.-Daily variation of horizontal intensity in gammas of the earth's magnetic field at Honolulu. Monthly averages for 10 selected quiet days of each month for the 10 years 1919-23 and 1929-33. 165th west meridian time.

The two sets of 10 years show very similar characteristics, giving support to the reality of the differences of range and of form pointed out above in figure 1. They incidentally illustrate in general (see also fig. 5 and 6 ) the known greater range of the daily variation for years of greater sunspot number, here 58 is the yearly average for the 10 years of figure 3 , as compared with 29 for the other 10 (fig. 2).

There is support, too, for the presence of other features such as the form of the January and December diurnal variations in the vicinity of the 8th hour and that for July in the vicinity of the 10th hour, which also appear to arise from some further influence than that of solar declination.

In view of the greater solar activity during the last two sunspot cycles than during the 20 years just discussed, it should be informative to compare the monthly averages of the daily variation for recent years with those shown in 


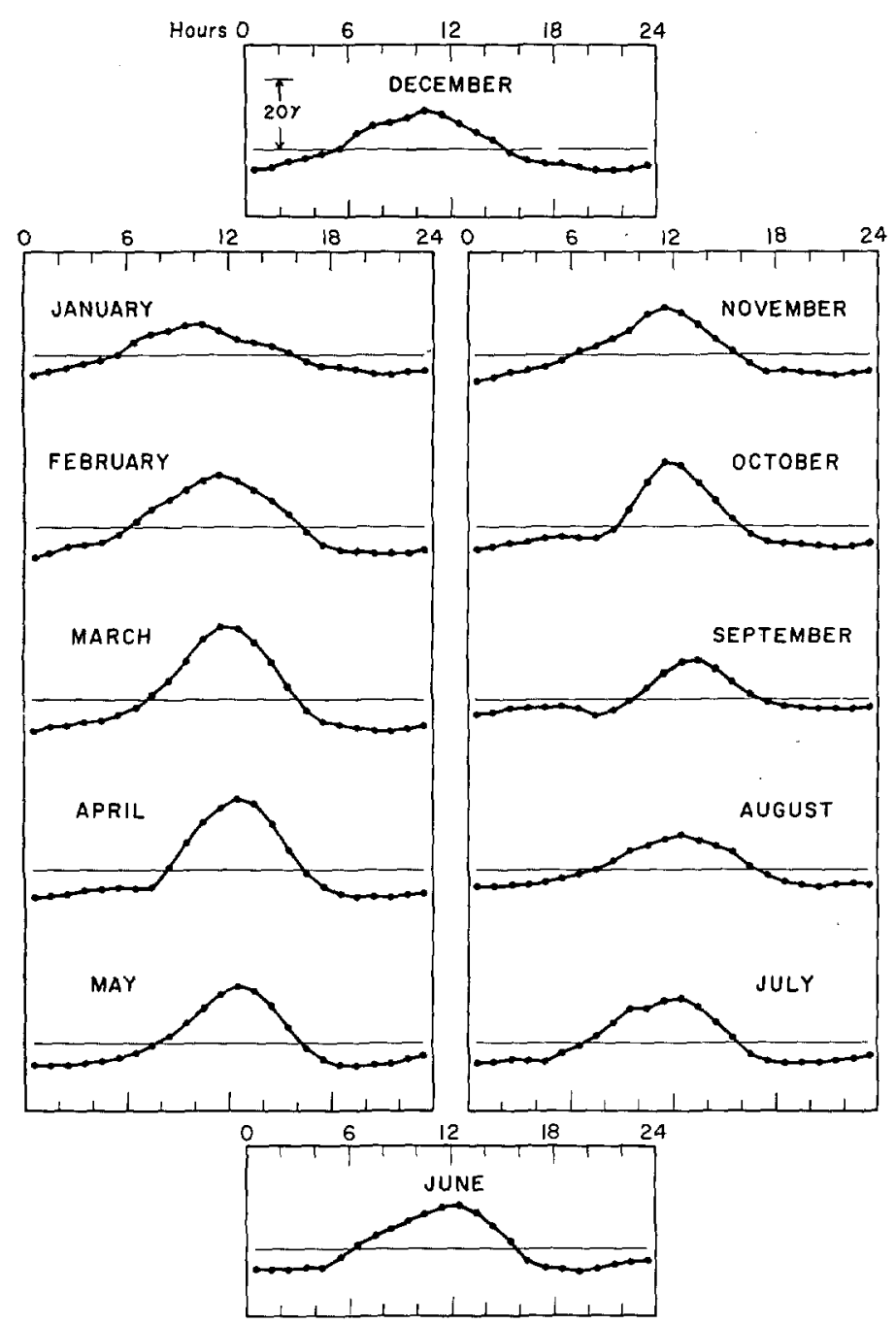

FIGURe 3.-Daily variation of horizontal intensity in gammas of the earth's magnetic field at Honolulu. Monthly averages for 10 selected quiet days of each month for the 10 years 1917, 1918, 1924-28, and 1934-36. 165th west meridian time.

figures 1,2 , and 3 . Similar figures, figures 4,5 , and 6 , were prepared for the 11 years $1948-58$.

There is an important difference, however, between these two sets of figures. Besides pertaining to only 11 years, these latter three figures use only the five international quiet days of each month instead of 10 selected quiet days. Tables of the diurnal variation are not given in the observatory yearbooks of recent years. However, for each month the average hourly values for the five international quiet days (which are selected on the basis of the Greenwich day) are given together with their mean, and the departures of these average values for the five quiet days from their mean were taken in the present work.

Therefore, in figure 4 these 11 years are represented, in each monthly average, by only 55 days instead of 200 days as in the montbly averages for the 20 years of figure 1. Similarly, the two sets of five and six years, into which these 11 years were divided in figures 5 and 6 , are represented by only 25 and 30 days for each monthly average,

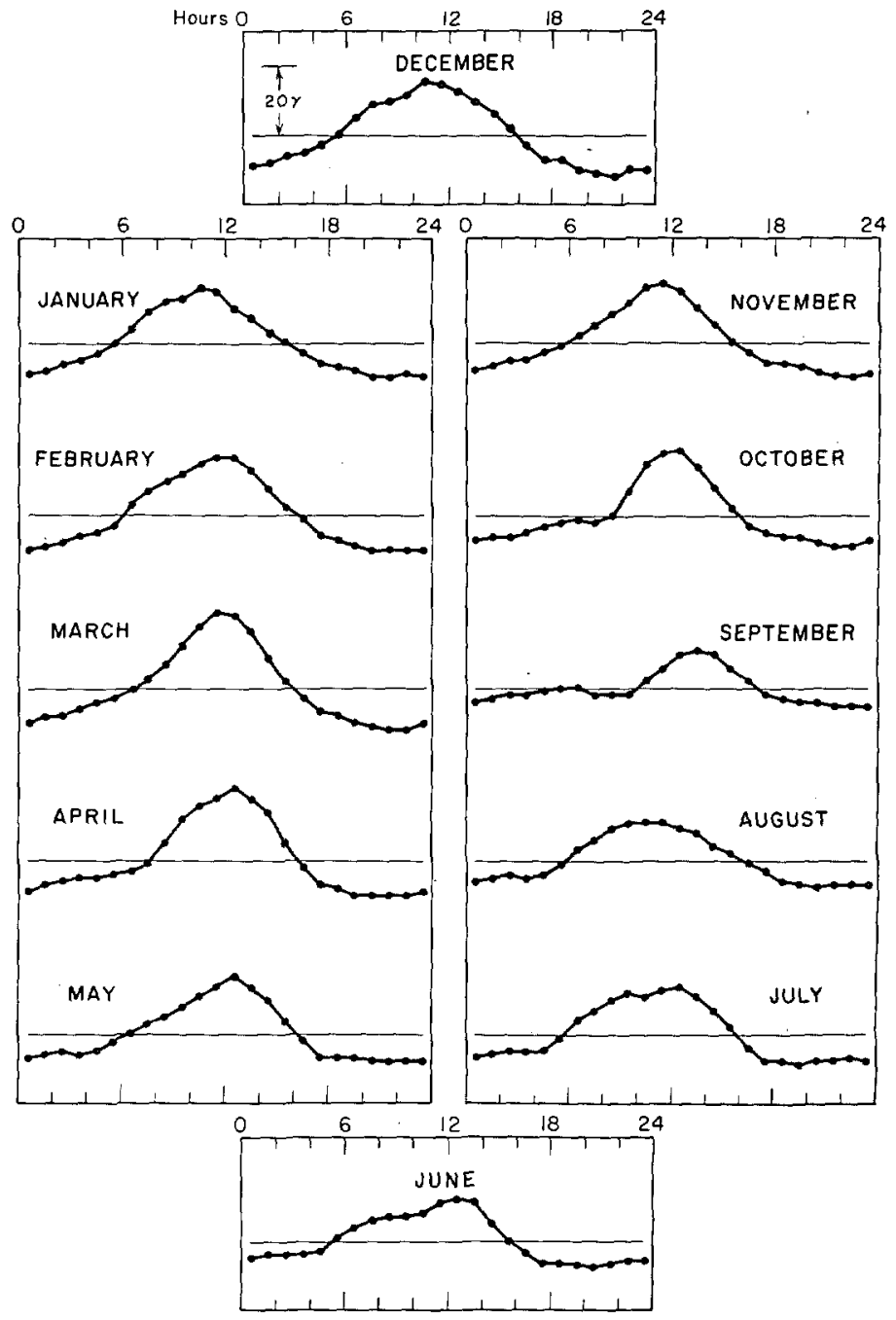

FIgURE 4.-Daily variation of horizontal intensity in gammas of the earth's magnetic field at Honolulu. Monthly averages for the five international quiet days of each month for the 11 years 1948-58. 165th west meridian time.

respectively. Hence one would expect that the results in figures 4, 5, and 6 should in general be less regular and less representative than those in figures 1,2 , and 3 . For the present purpose, where only pronounced features are being discussed, an approximate representation of the diurnal variation was felt to be adequate.

For each of the 11 years 1948-58, for each month separately, the hourly departures of the horizontal intensity were determined from the row for the mean of the five quiet days in the table of hourly values for the particular month in the corresponding yearbook for the Honolulu Magnetic Observatory issued by the U.S. Coast and Geodetic Survey. The 11 values for each hour for each. month were averaged, rounding the result to one gamma. These were corrected approximately for non-cyclic change, ${ }^{2}$ and the results plotted in figure 4 .

2 The last and first hours of the Greenwich day are the 13th and 14th hours 165th west meridian time. 


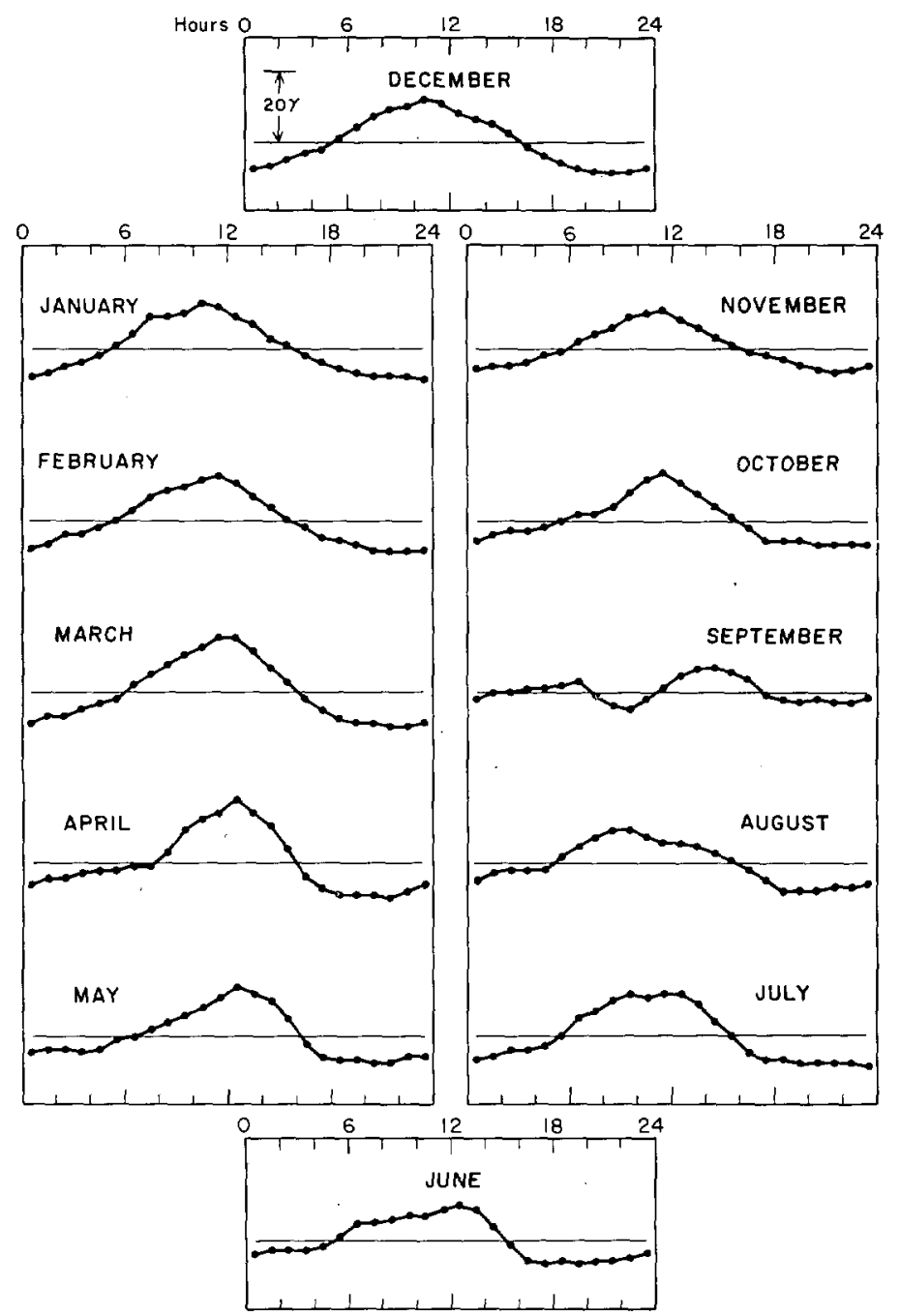

FIgURE 5.-Daily variation of horizontal intensity in gammas of the earth's magnetic field at Honolulu. Monthly averages for the five international quiet days of each month for the five years 1950-54. 165th west meridian time.

The monthly curves of figure 4 are, in general, similar to those of figure 1 showing similar differences between the different months. Those of figure 4 are of greater range than those of figure 1, as might be expected from the considerably greater yearly average sunspot number, namely 94 , for the 11 years of figure 4 than for the 20 years of figure 1, where the number was 43 .

August and September have appreciably smaller range than April and March, respectively, as was pointed out in figure 1, and also September and October again show a tendency toward a minimum in the vicinity of the 8th hour, extending later in September. In April, however, this tendency for such a minimum, if present, is weak.

Other similarities, such as the form of the July daily variation in the vicinity of the 10th hour, can be seen. The daily variation for January differs somewhat from that in figure 1, but a change of form has occurred between

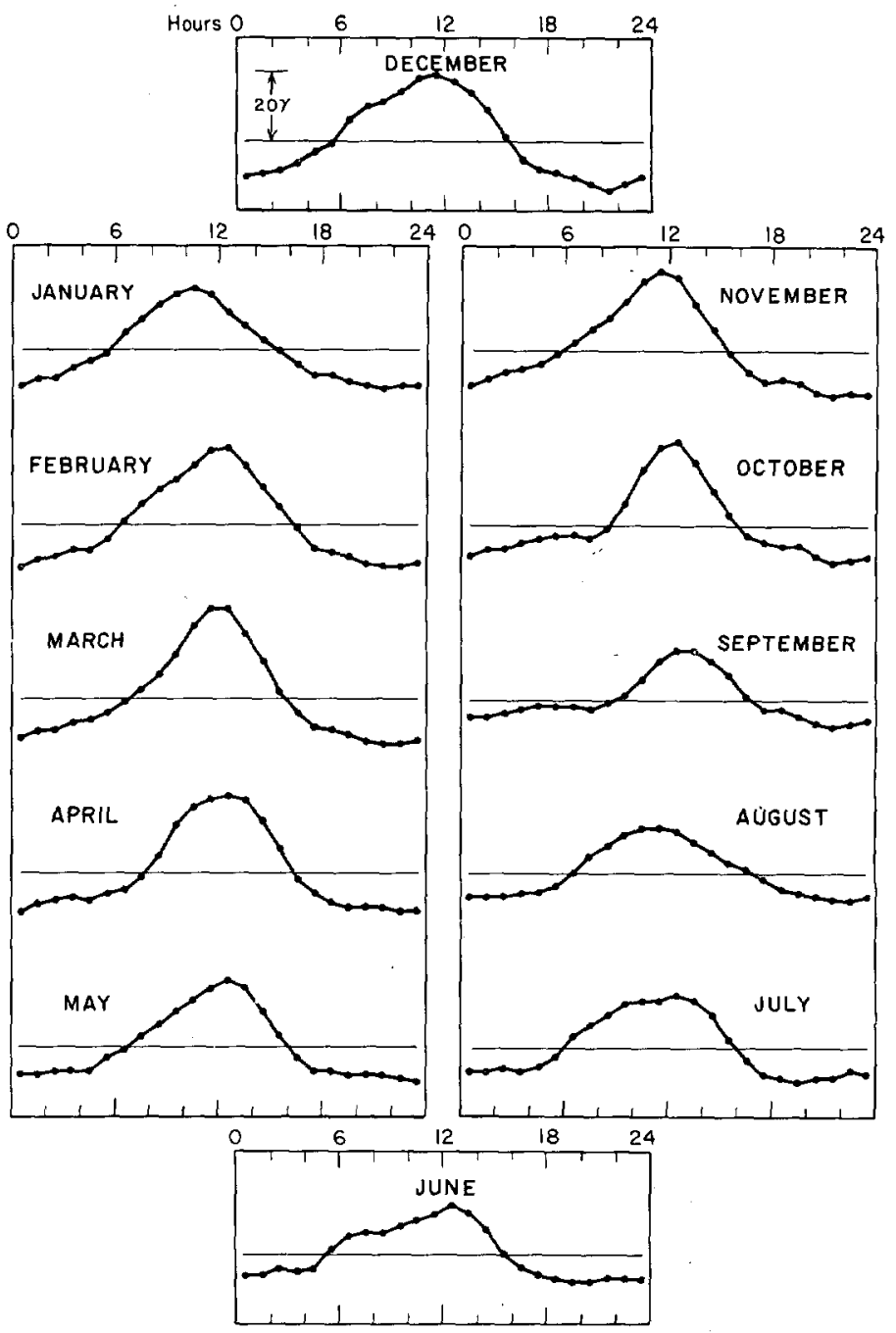

FigURE 6.-Daily variation of horizontal intensity in gammas of the earth's magnetic field at Honolulu. Monthly averages for the five international quiet days of each month for the six years 1948, 1949, 1955-58. 165th west meridian time.

December and March similar to that in figure 1. In general these 11 later years of greater average solar activity lend further support to the reality of the above-described average features of this daily variation.

To divide these 11 years into two sets involves working with a rather small amount of data. But the years near these two sunspot maxima had such high sunspot numbers that they are of special interest, even in rough results, and a division of the data has been made in figures 5 and 6 in the same manner as was done in figures 2 and 3.

In figure 5 are shown the results for $1950-54,{ }^{3}$ the five years preceding and including sunspot minimum (as in fig. 2), and in figure 6 for the remaining six years, 1948, 1949, 1955-58. They have been corrected approximately for non-cyclic change. They early average sunspot number

The data were not available for October 1954 
for the five years 1950-54 was 41, as compared with 29 for the corresponding 10 years of figure 2 or with 43 for the entire 20 years of figure 1 . The yearly average sunspot number for the six years of figure 6 was 138 , much higher than that, namely 58, for the corresponding years of figure 3 .

These two sets (figs. 5 and 6) each show the smaller range of the variation in August and September as compared with April and March, and also the tendency for a minimum in the vicinity of the 8 th hour in September and October (in fig. 5 pronounced and later in September and slight in October), but not in March and February. ${ }^{4}$

Summarizing, the results for these 11 years of higher average sunspot number, though based on considerably less data than those for the earlier 20 years, in general give support to the presence of the features pointed out in the data for the 20 years.

Thus it appears that in the average of a number of years both a difference in range and a difference in form of the daily variation between times of the same solar declination on opposite sides of the year can usually be seen in the monthly average daily variation of the horizontal intensity for quiet days at Honolulu. In a particular year, however, such a feature characteristic of the average behavior of a particular month may differ considerably from the average. The additional general observation that such differences in the daily variation of the field frequently occur from day to day suggests that one must look for the cause to some property of the atmosphere, where rapid change is possible but where seasonal influences may persist.

The differences seem to require corresponding differences in the ionospheric electric currents of the daily variation occasioned by something other than the intensity of solar radiation alone. These differences in turn may require respective differences in an atmospheric factor between the two times of year, probably differences in the largescale air circulation in the ionosphere with accompanying pressure, temperature, and density differences.

The variable behavior of the daily variation in the vicinity of the 8th hour has been mentioned. It is of interest to inquire how the variability of the hourly departures from month to month throughout the year depends upon the time of day, that is, which hourly departure varies most throughout the year. Using the 20 years of data for 10 selected quiet days of each month (fig. 1) the average values of the 12 intermonthly differences taken without regard to sign of the average departures of the horizontal intensity for each hour are shown in figure 7 .

In this figure a group of hours shows differences that are much larger than the others, and at first sight this group might seem to comprise the daylight hours. But there is

\footnotetext{
I In figure 6, accompanying the generally greater range with greater sunspot number, there seems to have been a tendency toward the overshadowing or masking of certain of the characteristic features discussed above. A preliminary study of a number of months of individual years suggests that this may be associated, at least in part, with the daytime enhancement of the daily variation in the years of high sunspot number, especially in 1957 and 1958, the years of highest sunspot number. It is hoped to study this further.
}

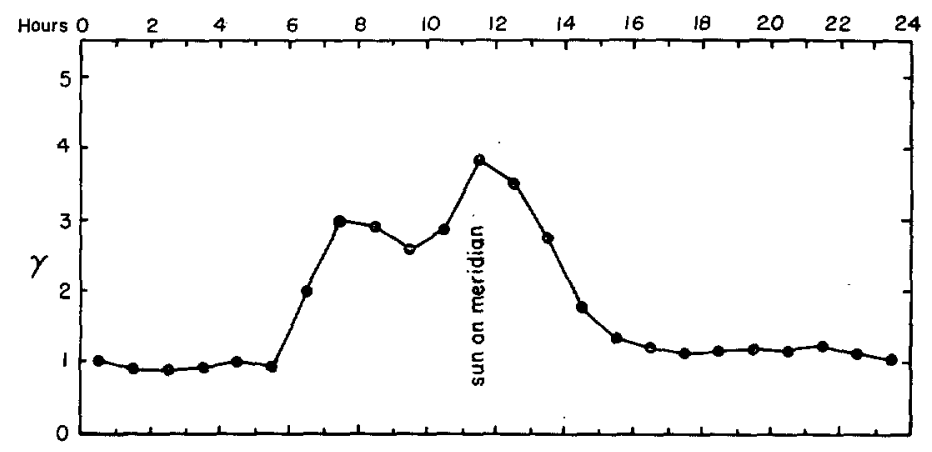

FigURe 7.--Average values of the 12 intermonthly differences, without regard to sign, of the average hourly departures of the horizontal intensity in gammas for each hour at Honolulu. Ten selected quiet days of each month; 20 years, 1917-36.

an asymmetry with respect to noon, indicating that it is something more than this. ${ }^{5}$ As the sun comes to the 7 th and 8 th hours, 165 th west meridian time, the average difference of the hourly departures from month to month becomes large, continuing large through the 14th hour, but then falling off rapidly, the values for the 15 th and 16th hours being appreciably smaller than those for the 8th and 9th. The daily maximum of the horizontal intensity in the yearly average comes at about noon on quiet days at Honolulu (see, for example, Vestine, Laporte, Lange, and Scott [10] and Nelson, Hurwitz, and Knapp [4]). Possibly the pattern of large-scale circulation in the lower ionosphere met with by the sun over the longitude range from roughly $75^{\circ} \mathrm{W}$. to $135^{\circ} \mathrm{W}$. is subject to especially large seasonal changes, and leads to a greater than average variability in the production of the daily magnetic variation as the sun moves over this longitude range.

In figure 8 the range of the daily variation, from figure 1, is shown for each month, the highest average hourly value minus the lowest average hourly value. This may be compared with the somewhat similar material presented by Howe [2]. (The years used in figs. 1-3 and 7-9 are included in the 35 years discussed by Howe.) In the average of these 20 years, maxima in the range occur in March and in October, while the smallest ranges occur in August or September and in January.

It is of interest also to inquire how the intermonthly change of the daily variation of the field varies throughout the year. In figure 9 are shown the values of the average, without regard to sign, of the 24 intermonthly differences of the hourly departures for each consecutive two months using the data of figure 1 .

The results shown in figures 8 and 9 are clearly not what would be expected from the regular change of solar declination alone. It would seem reasonable to suggest

\footnotetext{
5 The asymmetry of the ear th's field with respect to the meridian of Honolulu may contribute in some measure to the asymmetry shown in figure 7 , but this is not believed to be a contribution of major importance, largely from a consideration of the character of the differences themselves from month to month in figure 1.
} 


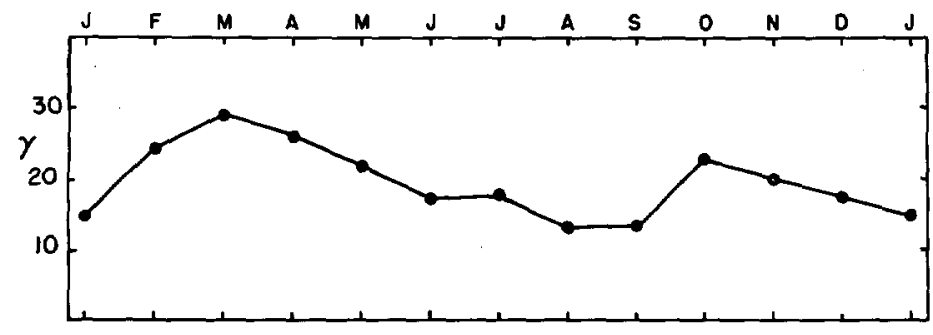

FIGURe 8.-Average monthly range of the daily variation of horizontal intensity in gammas (highest average hourly departure minus lowest average hourly departure, from figure 1) at Honolulu. Ten selected quiet days of each month; 20 years, 1917-36.

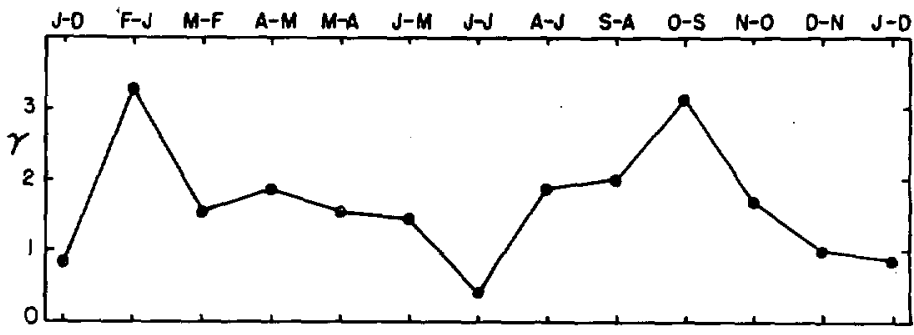

Frgure 9.-Average values of the 24 intermonthly differences, without regard to sign, of the average hourly departures of the horizontal intensity in gammas for consecutive months at Honolulu. Ten selected quiet days of each month; 20 years, 1917-36. that atmospheric conditions in the lower ionosphere, changing from day to day and with the seasons, influence the production of the daily variation of the field, and lead to changes of range and of form that follow the complex changes of the large-scale air circulation there. Kochanski [3] has recently surveyed what is known concerning the circulation in this region.

Of interest is the large intermonthly change indicated by figure 9 from January to February and from September to October. It suggests that at these times major changes occur, in the average, in the patterns of air circulation in the lower ionosphere, possibly the breaking up of a mid-winter regime in the first case, and an analog in this region of the setting in of the circumpolar vortex (Low) in the upper stratosphere in the second case. ${ }^{6}$ The intermonthly change is small near the two solstices.

\section{DISCUSSION AND CONCLUSIONS}

It should be possible through a daily study of the Honolulu (and other) magnetograms to determine when the major seasonal changes in the daily variation of the magnetic field occur; for example, at approximately what time, undoubtedly variable in some measure from year to year, the change from the average January type of daily variation to that of the average February type occurs. This could be compared with the large-scale characteristics of the daily meteorological maps at as bigh levels in the stratosphere as are available, noting particularly the time of breakdown of the stratospheric polar Low $[7,5]$. Similar comparisons could be made with other of the identifiable features in the magnetograms (such as the changes that occur from August to September and from September to October) that may be associated with changes of the atmospheric circulation in the lower ionosphere.

Such a study should of course be extended to the records of other observatories. Wulf and Hodge [15] have earlier indicated ways in which the records of the Tucson observatory might be studied from this point of view, taking

${ }^{B}$ Concerning such changes in the upper stratosphere see references [7] and [5] advantage of anomalous features of the daily variation there which were pointed out by Rooney [6]. Furthermore, it seems clear that some relation would be expected between the results of such a study for two observatories sufficiently close to one another as to be partially under the influence of the same large-scale pattern of air circulation in the lower ionosphere [14].

Geomagnetic disturbance, not mentioned in the above except indirectly in that geomagnetically quiet days were used, would frequently make difficult or impossible the use of the record for a particular day in the manner suggested here. But by taking advantage of the quiet and only slightly disturbed days it appears that one could follow the major seasonal changes in the quiet-day daily variation of the field sufficiently well to permit helpful comparison with the meteorological charts of the upper stratosphere. Moreover, in such a study, comparison could be made of the magnetically disturbed days with those showing abrupt change in the large-scale circulation in the charts of the upper stratosphere, in order to search for instances where magnetic disturbance may have arisen by dynamo action from large-scale irregular air motions in the lower ionosphere, since in some measure magnetic disturbance may arise in this way.

The emphasis in such a study as that suggested in this paper should undoubtedly be placed on the changes that occur. The patterns themselves of the large-scale circulation in the lower ionosphere may differ considerably from those in the upper stratosphere. But when a major change occurs, over a considerable portion of the hemisphere, in the pattern of large-scale circulation at one level, it seems probable that some accompanying change will occur at the other level. From this point of view, largescale change associated with the release of instability in the lower atmosphere might be reflected in a change in the lower ionosphere. On the other hand, changes of largescale circulation occurring in the lower ionosphere [11], possibly because of variable solar radiation absorbed there, might be accompanied by changes in the circulation lower down.

The author believes that there is an unusual opportunity here to extend the scope of meteorological research. 
Geomagnetic data are extensive, coming from the continuous daily recordings of the earth's magnetic field made at numerous observatories distributed widely over the surface of the earth. There seems to be a reasonable possibility that there may be in these records a storehouse of potentially useful information concerning changes in the largescale air circulation in the lower ionosphere that could be helpfully applied to the study of the atmosphere below.

\section{ACKNOWLEDGMENT}

The author gratefully acknowledges the encouragement received from Dr. Harry Wexler in this work.

\section{REFERENCES}

1. S. Chapman, "Regular Motions in the Ionosphere: Electric and Magnetic Relationships," Bulletin of the American Meteorological Society, vol. 42, No. 2, Feb. 1961, pp. 85-100.

2. H. H. Howe, "An Anomaly of the Magnetic Daily Variation at Honolulu," Journal of Geophysical Research, vol. 55, No. 3, Sept. 1950, pp. 271-274.

3. A. Kochanski, "Circulation and Temperatures at 70- to 100Kilometer Height," Journal of Geophysical Research, vol. 68, No. 1, Jan. 1, 1963, pp. 213-226.

4. J. H. Nelson, L. Hurwitz, and D. G. Knapp, "Magnetism of the Earth," U.S. Department of Commerce, Coast and Geodetic Survey Publication 40-1, 1962 (see figure 11, p. 25).

5. C. E. Palmer, "The Stratospheric Polar Vortex in Winter," Journal of Geophysical Research, vol. 64, No. 7, July 1959, pp. $749-764$.

6. W. J. Rooney, "Diurnal-Variation Anomalies at Tucson,"
Terrestrial Magnetism and Atmospheric Electricity, vol. 50, No. 3, Sept. 1945, pp. 175-184.

7. S. Teweles and F. G. Finger, "An Abrupt Change in Stratospheric Circulation Beginning in Mid-January 1958," Monthly Weather Review, vol. 86, No. 1, Jan. 1958, pp. 23-28.

8. D. van Sabben, "Ionospheric Current Systems Caused by Non-Periodic Winds," Journal of Atmospheric and Terrestrial Physics, vol. 24, Nov. 1962, pp. 959-974.

9. E. H. Vestine, "Seasonal Changes in Day-to-Day Variability of Upper Air Winds Near the 1.00-km. Level of the Atmosphere," Transactions of the American Geophysical Union, vol. 39, No. 2, Apr. 1958, pp. 213-223.

10. E. H. Vestine, L. Laporte, I. Lange, and W. E. Scott, "The Geomagnetic Field, Its Description and Analysis," Carnegie Institution of Washington Publication 580, 1947 (see figure 69, p. 157).

11. H. Wexler, "Rocket and Satellite Meteorology," IG Bulletin, No. 64, October 14-20, 1962, in Transactions, American Geophysical Union, vol. 43, No. 4, Dec. 1962 (see especially pp. 15-16).

12. O. R. Wulf, "On the Relation between Geomagnetism and the Circulatory Motions of the Air in the Atmosphere," Terrestrial Magnetism and Atmospheric Electricity, vol. 50, No. 3, Sept. 1945, pp. 185-197.

13. O. R. Wulf, "A Preliminary Study of the Relation between Geomagnetism and the Circulatory Motions of the Air in the Atmosphere," Terrestrial Magnetism and Atmospheric Electricity, vol. 50, No. 4, Dec. 1945, pp. 259-278.

14. O. R. Wulf, "A Possible Atmospheric Solar Effect in Both Geomagnetism and Atmospheric Electricity," Terrestrial Magnetism and Atmospheric Electricity, vol. 51, No. 1, Mar. 1946, pp. 85-87.

15. O. R. Wulf and M. W. Hodge, "On the Relation between Variations of the Earth's Magnetic Field and Variations of the Large-Scale Atmospheric Circulation," Journal of Geophysical Research, vol. 55, No. 1, Mar. 1950, pp. 1-20. 